\title{
Conteúdo de Energia Líquida para Mantença e Ganho do Capim-Elefante e Mudanças na Composição Corporal de Novilhos em Pastejo, Durante a Estação Chuvosa
}

\author{
Carlos Augusto de Alencar Fontes ${ }^{1}$, Rildon Carlos de Oliveira², Eleonora D'Ávila Erbesdobler ${ }^{3}$, \\ Domingos Sávio de Queiroz ${ }^{4}$, Cláudio Teixeira Lombardi ${ }^{5}$
}

\begin{abstract}
RESUMO - Foram determinados os conteúdos de energia líquida para mantença $\left(\mathrm{EL}_{\mathrm{m}}\right)$ e ganho $\left(\mathrm{EL}_{\mathrm{g}}\right)$ do capim-napier, submetido a pastejo rotacionado, e as mudanças nas concentrações corporais e do ganho de proteína, gordura e energia, de 36 novilhos 3/4Gir-Holandês pastejando a forrageira, durante o período chuvoso. Metade dos animais teve o tempo de pastejo restrito a quatro horas diárias, para se limitar o consumo de energia a nível próximo ao de mantença e metade teve acesso irrestrito à pastagem. Seis novilhos foram abatidos no início do experimento, para se determinar a composição corporal inicial, e seis (três de cada tratamento), a cada 35 dias. Foram ajustadas equações de predição das mudanças na composição corporal, com o aumento do peso vivo, por regressão dos logaritmos dos conteúdos corporais de proteína e gordura, em função do logaritmo do peso de corpo vazio. Derivando-se essas equações, foram obtidas equações de predição da composição do ganho de peso. As concentrações de energia foram estimadas a partir dos teores de proteína e gordura e dos respectivos equivalentes calóricos. Por regressão da energia retida (ER), em função da energia metabolizável (EM) consumida, estimou-se a eficiência de utilização da EM para ganho $\left(K_{g}\right)$, correspondente ao coeficiente de regressão, e a exigência de EM para mantença (nível de ingestão de $\mathrm{EM}$, para $\mathrm{ER}=0$ ). A eficiência de utilização de $\mathrm{EM}$ para mantença $\left(\mathrm{K}_{\mathrm{m}}\right)$ foi obtida pela relação: $\mathrm{K}_{\mathrm{m}}=\mathrm{EL}_{\mathrm{m}} / \mathrm{EM}_{\mathrm{m}}$. Os conteúdos de $\mathrm{EL}_{\mathrm{m}}$ e $E L_{\mathrm{g}}$ do capim-napier foram determinados, respectivamente, pelos produtos de $\mathrm{K}_{\mathrm{m}}$ e $\mathrm{K}_{\mathrm{g}}$ pelo conteúdo de EM do pasto, obtendo-se, respectivamente, os valores 1,02 e 0,59 Mcal/kg de MS. As concentrações de proteína corporais e do ganho mantiveram-se em níveis mais elevados e as concentrações de gordura e energia em níveis mais baixos que os valores relatados, no Brasil, para animais zebuínos e mestiços Europeu-Zebu, apresentando ganhos mais elevados.
\end{abstract}

Palavras-chave: capim-napier, composição corporal, conteúdo de energia líquida, estação chuvosa, novilhos

\section{Net Energy Content for Maintenance and Weight Gain of Elephantgrass and Changes on Body Composition of Grazing Steers During the Rainy Season}

\begin{abstract}
The net energy content for maintenance $\left(\mathrm{NE}_{\mathrm{m}}\right)$ and gain $\left(\mathrm{NE}_{\mathrm{g}}\right)$ of the napiergrass, under rotational grazing, as well as the changes on protein and fat concentrations in body and in weight gain of 36 3/4 Gyr-Holstein steers, grazing the forage, during the rainy season were determined. Half of steers had grazing time restricted to four hours daily, to limit energy intake to a level close to the maintenance level, and half had free access to the pasture. Six steers were slaughtered at begining of the trial, to determine initial body composition, and six (three from each treatment), at each subsequent 35 day. Prediction equations of the changes of body composition, with increase of body weight, were fitted by regression of $\log _{10}$ body content of protein and fat on $\log _{10}$ empty body weight. By differentiation of those equations, the prediction equations of composition of weight gain were obtained. The energy concentrations were estimated from protein and fat content and respective calorie equivalents. By regression of retained energy (RE) on metabolizable energy (ME) intake, the efficiency of ME utilization for gain, as the regression coeficient, and the ME requirement for maintenance (level of ME intake for RE $=0$ ) were estimated. The efficiency of utilization of $\mathrm{ME}$ for maintenance $\left(\mathrm{K}_{\mathrm{m}}\right)$ was obtained by the ratio: $\mathrm{K}_{\mathrm{m}}=\mathrm{NE}_{\mathrm{m}} / \mathrm{ME}_{\mathrm{m}}$. The $\mathrm{NE}_{\mathrm{m}}$ and $\mathrm{NE}$ g of napiergrass were determined, respectively, as the products of $\mathrm{K}_{\mathrm{m}}$ and $\mathrm{K}_{\mathrm{g}}$ to $\mathrm{ME}$ content of the forage, and the values 1.02 and $0.59 \mathrm{Mcal} / \mathrm{kg}$ dry matter, respectively, were obtained. The protein concentrations in the body and in body weight gain remained in higher levels and the fat energy concentrations remained in lower levels than those reported, in Brazil, for zebu and crossbred steers showing higher weight gains.
\end{abstract}

Key Words: body composition, grazing, napiergrass, net energy content, rainy season, steers

\section{Introdução}

O conteúdo energético dos alimentos para bovinos de corte é freqüentemente expresso em termos de energia digestível (ED), nutrientes digestíveis to- tais (NDT) ou energia metabolizável (EM).

O NRC (1996) pondera que a ED, embora reflita a digestibilidade da dieta, considerando-se as perdas energéticas fecais, é pouco precisa na avaliação dos alimentos, por desconsiderar perdas importantes de

\footnotetext{
${ }^{1}$ Professor Titular, PhD - Universidade Estadual do Norte Fluminense. Pesquisador CNPq. E.mail: cafontes@uenf.br

2Zootecnista, MS - Autônomo.

3Zzootecnista, MS - Aluna do curso de Pós-Graduação em Biociências - UENF.

${ }^{4}$ Pesquisador da EPAMIG - D Sc

5 Zootecnista, MS - Técnico de Nível Superior - UENF. E.mail: Iombardi@uenf.br
} 
energia, associadas à digestão e ao metabolismo do alimento. Por isso, a ED superestima o valor de alimentos com altos teores de fibra e subestima o valor de alimentos altamente digestíveis, como os grãos. O NDT não teria vantagem sobre a ED, podendo ser convertido nesta, utilizando-se a relação: $1 \mathrm{~g}$ de $\mathrm{NDT}=4,4 \mathrm{kcal}$ de ED.

A EM, obtida deduzindo-se do conteúdo de ED as perdas energéticas na forma de gases (EG) e urina (EU), teria as mesmas limitações da ED, uma vez que a EG e a EU são altamente previsíveis, a partir da ED, existindo, por isso, alta correlação entre os valores de ED e EM. Embora reconhecendo a existência de variações na relação EM/ED dos alimentos, em função de diferenças nos níveis de consumo e nas taxas de passagem e de degradação, na prática, os padrões alimentares têm estimado a EM a partir da ED, utilizando-se coeficientes fixos. O CSIRO (1990) adota a relação: $\mathrm{EM}=0,81 \mathrm{X} \mathrm{ED}$, muito semelhante à relação: EM = 0,82 X ED, utilizada pelo NRC (1996), que adota também, em suas tabelas de composição de alimentos, a relação: $1 \mathrm{~g}$ de NDT $=3,9 \mathrm{kcal}$ de EM.

Atualmente, o critério mais adequado e amplamente utilizado para expressar os requerimentos de energia dos animais e o valor energético dos alimentos, nos cálculos de ração, é o sistema de energia líquida (EL). Esta deduz do conteúdo de EM as perdas energéticas na forma de calor, geradas no processo de fermentação ruminal e metabolismo dos produtos absorvidos da fermentação/digestão.

O sistema de EL apresenta as vantagens fundamentais de estabelecer os requerimentos dos animais de forma independente da dieta e de estimar, separadamente, o valor dos alimentos para as diferentes funções fisiológicas (mantença, ganho de peso, lactação e gestação), utilizando-se coeficientes específicos de eficiência de utilização da energia para as diferentes funções. O NRC (1996), ao estabelecer os requerimentos energéticos de gado de corte, converte, inicialmente, as exigências de energia para lactação $\left(E L_{1}\right)$ e gestação $\left(E L_{y}\right)$ em energia líquida para mantença $\left(\mathrm{El}_{\mathrm{m}}\right)$, utilizando-se coeficientes específicos. Desta forma, o valor energético dos alimentos pode ser adequadamente descrito utilizando-se apenas os valores de $E L_{m}$ e EL para ganho $\left(E L_{g}\right)$.

A adoção do sistema requer o conhecimento dos conteúdos de energia líquida dos alimentos, para as diferentes funções, e das exigências dos animais, as quais variam em função da raça, do sexo, da maturi- dade fisiológica, da composição do ganho, do grau de acabamento exigido pelo mercado, do nível de alimentação prévia, do clima, entre outros, além do nível de produção e da condição fisiológica do animal.

Um volume crescente de pesquisas tem sido dirigido, no Brasil, ao estabelecimento das exigências nutricionais de gado de corte (Salvador, 1980; Teixeira, 1984; Gonçalves, 1988; Lana et al., 1992a, b, c; Pires et al., 1993a, b; Soares, 1994; Fontes, 1995; Boin, 1995; Signoretti et al., 1999; Paulino et al., 1999a, b; Rocha \& Fontes, 1999). Há, entretanto, carência absoluta de estudos voltados à determinação do conteúdo de energia líquida dos alimentos utilizados, o qual pode ser fortemente influenciado por fatores como clima, solo, espécie forrageira, entre outros.

Tendo em vista a grande importância das pastagens no sistema de produção de gado de corte adotado no Brasil, torna-se relevante o conhecimento do conteúdo de energia líquida, para mantença e ganho, das principais forrageiras de interesse, com vistas ao estabelecimento de estratégias adequadas de suplementação que possam elevar a eficiência nutricional e econômica dos suplementos empregados. Essas determinações devem ser realizadas preferencialmente em condição de pastejo, em que é possibilitado ao animal exercer maior seletividade do alimento ingerido.

A composição corporal do animal e do tecido ganho em determinado intervalo de tempo dependem de fatores como idade do animal, raça, sexo, grau de maturidade fisiológica e nível nutricional. As mudanças da composição corporal dos animais, com o aumento do peso corporal, têm sido descritas ajustandose equações alométricas do tipo $\mathrm{y}=\mathrm{ax}$, em que $\mathrm{y}$ seria o conteúdo do componente corporal (proteína, gordura etc.) e x o peso de corpo vazio (PCVZ). Esta equação tem sido linearizada por transformação logarítmica, chegando-se a equações lineares do tipo $y=a+b \log x$ (ARC, 1980). Por derivação das equações encontradas, obtêm-se equações que permitem estimar o acréscimo do componente considerado (proteína, gordura, etc.) por kg de ganho de PCVZ.

É crescente o volume de informações no Brasil que descrevem as mudanças na composição corporal e do ganho de bovinos de diferentes grupos genéticos, alimentados em confinamento com rações completas, com o aumento do peso vivo (Lana et al., 1992a; Pires et al., 1993a, b; Boin, 1995; Fontes, 1995; Jorge, et al., 1999; Paulino et al., 1999b; Signoretti et al., 1999; 
Freitas et al., 2000; Berndt et al., 2002). Entretanto, há carência de informações referentes a bovinos mantidos em regime exclusivo de pastejo, em que os ganhos médios de peso, durante a estação chuvosa, situam-se entre 500 e 700 g/dia.

Esta pesquisa foi conduzida com os objetivos de determinar o conteúdo de energia líquida para mantença e ganho do capim-elefante, submetido a pastejo rotacionado, durante a estação chuvosa, e avaliar as mudanças na composição corporal, e do ganho, com o aumento do peso vivo, de novilhos $3 / 4 \mathrm{Gir}$ - 1/4 Holandês pastejando a forrageira.

\section{Material e Métodos}

A pesquisa foi realizada na Fazenda Experimental da EPAMIG, em Leopoldina, MG, e teve duração de 175 dias, coincidindo com o período chuvoso, de outubro a maio.

Adotou-se a técnica de abate comparativo, utilizando-se 36 bovinos machos castrados, 3/4 Gir-Holandês, criados em regime exclusivo de pastejo, com média de 20 meses de idade e peso vivo inicial de 332 $\pm 37 \mathrm{~kg}$.

Os novilhos foram mantidos em pastagem de capim-elefante (Pennisetum purpureum, Schum.) cv. Napier, com suplementação mineral. Adotou-se o pastejo rotacionado, com quatro dias de ocupação e 32 dias de descanso.

Os animais foram divididos em três blocos, de acordo com o peso inicial, com 12 animais por bloco. A seguir, dois animais de cada bloco fora alocados, aleatoriamente, em seis grupos de abate, ficando cada grupo constituído por seis animais. Um dos grupos foi abatido no início do experimento (grupo referência-GR).

A relação média entre o peso de corpo vazio (PCVZ) e peso vivo (PV) determinada nos animais GR foi utilizada para se estimar o PCVZ inicial dos animais remanescentes. Do mesmo modo, a composição média corporal dos animais de cada bloco do grupo referência (concentração de proteína, gordura e energia) foi utilizada como estimativa da composição corporal inicial dos animais restantes.

Os cinco grupos de animais experimentais remanescentes foram designados, por sorteio, para abate, realizado em intervalos de 35 dias, constituindo os grupos de abate $A_{1}, A_{2}, A_{3}, A_{4}$ e $A_{5}$, abatidos 35,70 , 105,140 e 175 dias, respectivamente, após o início do experimento.
Três animais de cada grupo de abate, um de cada bloco, foram designados, por sorteio, para receberem os tratamentos:

1. Pastejo ad libitum até o abate (AL);

2. Pastejo restrito (PR), de forma a se manter o consumo de energia próximo ao nível de mantença, com pequeno ganho de peso.

Os animais PR tiveram acesso à pastagem durante apenas 4 horas diárias, de 6 às 10 h, para se manter a ingestão de alimento em nível pouco acima da exigência de mantença, admitindo-se que esse tempo de pastejo permitiria a ingestão de alimento em nível acima da mantença, conforme verificado em observações preliminares. Após o tempo de pastejo, esses novilhos permaneceram durante o resto do dia em currais providos de área coberta, com acesso à água. Os animais AL foram mantidos durante todo o dia na pastagem, tendo acesso, a cada dia, aos mesmos piquetes dos animais PR.

Os animais já vinham sendo mantidos em pastagens de capim-elefante antes do período experimental, sendo colocados nos piquetes experimentais sete dias antes do abate inicial. Durante o período experimental, procurou-se manter taxa de lotação equivalente a 5,5 animais por ha.

A disponibilidade de forragem no início do período de ocupação dos piquetes foi determinada dez vezes durante o período experimental.

O consumo alimentar individual foi estimado seis vezes durante o período experimental, utilizando-se a relação produção fecal/indigestibilidade da matéria seca alimentar. A produção fecal foi determinada utilizando-se o indicador óxido crômico. Em cada determinação, 5 g de $\mathrm{Cr}_{2} \mathrm{O}_{3}$ foram fornecidos a cada novilho, duas vezes ao dia, às 10 e $15 \mathrm{~h}$, acondicionados em cartucho de papel, que era colocado diretamente no esôfago do animal, durante 16 dias consecutivos. Após os primeiros oito dias (período de padronização), iniciou-se o período de amostragem, com duração de oito dias, em que amostras fecais foram obtidas por coleta retal, duas vezes ao dia, no momento de fornecimento do $\mathrm{Cr}_{2} \mathrm{O}_{3}$.

As dosagens de cromo foram feitas pelo método colorimétrico, fazendo-se digestão nitro-perclórica e leitura em espectrofotômetro UV visível a $440 \mathrm{~nm}$ (aparelho SPEKOL UV visível).

As amostras da dieta foram obtidas durante os oito dias de coleta das amostras fecais (seis vezes durante o período experimental), utilizando-se quatro 
novilhos fistulados no esôfago, segundo a técnica descrita por Bishop \& Froseth (1970). As bolsas de coleta foram feitas de lona impermeável, contendo malha de náilon no fundo, para drenagem de saliva.

A digestibilidade das extrusas foi determinada pelo método in vitro (Tilley \& Terry, 1963). O líquido de rúmen utilizado foi coletado de animal alimentado com capim-elefante, por um período mínimo de dez dias antes da coleta.

Os consumos diários médios individuais de energia digestível (ED), em cada período de 35 dias, foram calculados a partir dos conteúdos de energia da extrusa e das amostras compostas individuais de fezes, bem como dos valores de consumo e excreção fecal individuais médios diários no período. O consumo de energia metabolizável (EM) foi estimado utilizando-se a relação: $\mathrm{EM}=$ 0,82 x ED (NRC, 1996).

Para determinação da energia corporal retida pelos animais dos dois tratamentos, realizaram-se, ao abate, a pesagem e amostragem de todos os componentes corporais, incluindo-se o sangue, o couro, a cabeça, a cauda e os pés, para posterior determinação dos teores de proteína, gordura e de água neles contidos, de forma a se determinar a composição do corpo vazio (livre de digesta). O peso de corpo vazio (PCVZ) foi determinado pela soma dos pesos de carcaça, sangue, couro, cauda, pés, vísceras e órgãos.

As duas meia-carcaças foram pesadas quentes e levadas à câmara fria, onde permaneceram por, aproximadamente, 18 horas à temperatura de $-5^{\circ} \mathrm{C}$. Após esse tempo, foram coletadas amostras individuais da carcaça esquerda, correspondentes à seção da $9^{\text {a }}$ a $11^{\text {a }}$ costela, segundo Hankins \& Howe (1946). As seções foram dissecadas, determinando-se as proporções de músculos, tecido adiposo e ossos nelas contidas, a partir das quais se estimaram as proporções correspondentes na carcaça, utilizando-se as equações propostas por esses autores.

As amostras de carne (120 g), tecido adiposo (200 g), vísceras (120 g) e composta de órgãos (200 g), após moídas, e as de couro, ossos e cauda (120 g), após seccionadas, foram colocadas em vidros com capacidade de $500 \mathrm{~mL}$ e levadas à estufa a $105^{\circ} \mathrm{C}$, durante 72 a 96 horas, para determinação da matéria seca gordurosa (MSG). Em seguida, as amostras foram submetidas a um processo de extração de gordura com éter de petróleo, conforme descrito por Kock \& Preston (1979), obtendo-se a matéria seca prédesengordurada (MSPD). As amostras pré- desengorduradas foram, posteriormente, processadas em moinho de bola, antes de se proceder às determinações de nitrogênio e extrato etéreo.

As amostras de sangue (400 g) foram acondicionadas em pirex e levadas à estufa de ventilação forçada a $55-60^{\circ} \mathrm{C}$, durante 48 horas, para determinação da matéria pré-seca, sendo processadas em moinho de bola.

As análises dos teores de nitrogênio total foram feitas em aparelho semimicro Kjeldahl e as de extrato etéreo, em aparelho Goldfish, conforme metodologia descrita por Silva (1990). O conteúdo de proteína foi determinado a partir do de nitrogênio total, utilizando-se o fator 6,25 .

O conteúdo total de gordura da amostra foi obtido somando-se a gordura removida no prédesengorduramento com o extrato etéreo residual.

Os conteúdos de proteína e gordura no corpo vazio foram determinados somando-se seus conteúdos na carcaça, nos órgãos, nas vísceras, no sangue, no tecido adiposo interno, na cabeça, nos pés, na cauda e no couro.

A determinação do conteúdo corporal de energia foi feita a partir dos conteúdos corporais de proteína e gordura e dos respectivos equivalentes calóricos: 5,6405 e 9,3929 (ARC, 1980).

A retenção de energia dos animais dos dois tratamentos foi determinada subtraindo-se do conteúdo corporal final de energia, determinado após o abate de cada animal, o seu conteúdo inicial estimado de energia. Este foi calculado com base no peso vivo inicial e na relação peso vivo/PCVZ e composição corporal observados nos animais referência, pertencentes ao mesmo bloco. A retenção diária de energia foi expressa por unidade de tamanho metabólico.

A exigência de energia metabolizável para mantença $\left(E M_{m}\right)$ foi determinada pela regressão da energia retida (ER), em função do consumo de energia metabolizável (EM), em kcal/dia, por unidade de tamanho metabólico, para o nível zero de retenção de EM, segundo o NRC (1996). O tamanho metabólico foi expresso como $\mathrm{kg} \mathrm{PCVZ}^{0,75}$.

Para predição dos conteúdos corporais de proteína e gordura, em função do aumento do peso corporal, foram ajustadas equações de regressão dos logaritmos dos conteúdos corporais de proteína e gordura (kg), em função do logaritmo do PCVZ (kg), segundo o ARC (1980), utilizando-se informações referentes aos animais do abate inicial e do tratamento AL (21 animais). 
Para as conversões de PV em PCVZ, ajustou-se equação de regressão do PCVZ, em função do PV. A eficiência de utilização da energia metabolizável do capim-napier para mantença $\left(\mathrm{K}_{\mathrm{m}}\right)$ foi determinada como o coeficiente $\mathrm{K}_{\mathrm{m}}=\frac{\mathrm{El}_{\mathrm{m}}}{\mathrm{EM}_{\mathrm{m}}}$, segundo o NRC (1996), em que $\mathrm{EL}_{\mathrm{m}}$ corresponde à exigência de $\mathrm{EL}$ para mantença dos animais, determinada por Fontes et al. (2005) e $E M_{m}$ é a exigência de $E M$ para mantença, determinada neste trabalho.

A eficiência de utilização da EM para ganho $\left(\mathrm{K}_{\mathrm{g}}\right)$ corresponde ao coeficiente de regressão (inclinação) da equação de regressão da energia retida, em função do consumo de EM (NRC, 1996).

Os conteúdos de EL para mantença $\left[\mathrm{EL}_{\mathrm{m}}\right]$ e de EL para ganho $\left[\mathrm{EL}_{\mathrm{g}}\right]$ do capim-napier foram obtidos multiplicando-se as respectivas eficiências de utilização da EM $\left(K_{m}\right.$ e $\left.K_{g}\right)$ pelo conteúdo estimado e EM da forrageira.

Outros detalhes da metodologia podem ser obtidos em Fontes et al. (2005).

\section{Resultados e Discussão}

Efetuando-se a regressão da energia retida, em função do consumo de energia metabolizável (EM), por unidade de tamanho metabólico (kg PCVZ $\left.{ }^{0,75}\right)$, chegou-se à equação:

$E R=-36,80281986+0,36982265 X ; r^{2}=0,7(P<0,01)$,

em que: $\mathrm{ER}=$ energia retida por kg $\mathrm{PCVZ}^{0,75}$; $\mathrm{X}=$ consumo de EM por kg PCVZ ${ }^{0,75}$

O coeficiente de regressão (inclinação) da equação obtida corresponde à estimativa da eficiência de utilização da EM para ganho $\left(\mathrm{K}_{\mathrm{g}}\right)$, conforme o NRC (1996). Portanto, para o capim-napier utilizado no presente trabalho, $\mathrm{K}_{\mathrm{g}}=0,36982265$.

A equação acima permite, ainda, determinar o nível de ingestão de EM em que ocorre retenção zero de energia no corpo, ou seja, quando não há ganho ou perda de energia pelo animal. Este nível de ingestão de energia corresponde à exigência de EM para mantença $\left(E_{m}\right)$ do animal (NRC, 1996). Fazendo-se, portanto, $\mathrm{ER}=0$, na equação, obteve-se:

$$
\mathrm{EM}_{\mathrm{m}}=99,515 \mathrm{kcal} / \mathrm{kg} \mathrm{PCVZ}^{0,75}
$$

Para os mesmos animais, pastejando os mesmos piquetes de capim-napier, Fontes et al. (2005) determinaram a exigência de energia líquida para mantença $\left(\mathrm{EL}_{\mathrm{m}}\right)=63,27 \mathrm{kcal} / \mathrm{kg} \mathrm{PCVZ}{ }^{0,75}$, que corresponde ao metabolismo em jejum dos animais, ou seja, à produção de calor para o nível zero de ingestão de energia.

A eficiência de utilização da EM para mantença corresponde ao quociente $\mathrm{K}_{\mathrm{m}}=\mathrm{EL}_{\mathrm{m}} / \mathrm{EM}_{\mathrm{m}}$, segundo o NRC (1996). Para o capim-napier, o valor obtido foi: $\mathrm{K}_{\mathrm{m}}=63,27 / 99,5=0,635$.

Partindo-se do conteúdo de EM do capim-napier utilizado neste trabalho, determinado por Fontes et al. (2005), equivalente a $1,617 \mathrm{Mcal} / \mathrm{kg}$ de MS, e dos valores de $\mathrm{K}_{\mathrm{m}}$ e $\mathrm{K}_{\mathrm{g}}$ obtidos, chegou-se aos conteúdos de $\mathrm{EL}_{\mathrm{m}} \mathrm{e}$ $\mathrm{EL}_{\mathrm{g}}$ da forrageira, conforme discriminado abaixo:

$\left[\mathrm{EL}_{\mathrm{m}}\right]=[\mathrm{EM}] * \mathrm{Km} .\left[\mathrm{EL}_{\mathrm{m}}\right]=1,617 * 0,635=1,03 \mathrm{Mcal} / \mathrm{kgdeMS}$ $\left[\mathrm{EL}_{\mathrm{g}}\right]=[\mathrm{EM}] * \mathrm{~K}_{\mathrm{g}} \therefore\left[\mathrm{EL}_{\mathrm{g}}\right]=1,617 * 0,3698=0,59 \mathrm{Mcal} / \mathrm{kgdeMS}$

Não foram encontradas na literatura brasileira informações referentes aos conteúdos de $\mathrm{EL}_{\mathrm{m}}$ e $\mathrm{EL}_{\mathrm{g}}$ do capim-napier. Os resultados deste trabalho, referentes ao capim-napier pastejado em intervalos de 35 dias, foram, entretanto, muito próximos aos valores apresentados pelo NRC (1996), em suas tabelas. Para o capim-napier, com 30 dias de rebrota, o NRC (1996) apresenta valores de $\mathrm{EL}_{\mathrm{m}}$ e $\mathrm{EL}_{\mathrm{g}}$ de 1,14 e 0,58 Mcal/kg de MS, respectivamente. Para o mesmo capim, com 60 dias de rebrota, os valores correspondentes são 1,07 e 0,52 .

De forma coerente com os valores energéticos da forragem encontrados neste trabalho, os animais pastejando a gramínea ad libitum, como alimento exclusivo, tiveram o ganho de peso apenas moderado de 516,5 g por dia, durante 175 dias de pastejo, no período das águas (outubro a maio), conforme relatado por Fontes et al. (2005).

Com o objetivo de se verificar as mudanças da composição corporal e da composição do ganho dos animais, com a elevação do peso corporal, foram ajustadas equações de regressão do logaritmo do conteúdo corporal de proteína e gordura, em kg, em função do logaritmo do PCVZ. Foram utilizadas informações referentes aos seis animais abatidos no início do experimento e aos 15 animais do tratamento pastejo ad libitum (AL), totalizando 21 animais.

Os parâmetros das citadas equações são apresentados na Tabela 1. 
Tabela 1 - Parâmetros das equações de regressão do logaritmo dos conteúdos $(\mathrm{kg})$ de proteína e de gordura, em função do logaritmo do peso de corpo vazio (PCVZ), em kg

Table 1 - Parameters of regression equations of the $\log _{10}$ empty body content $(\mathrm{kg})$ of protein and fat on $\log _{10}$ empty body weight (EBW), in $\mathrm{kg}$

Componente Parâmetros das equações de regressão

Component Parameters of regression equations

\begin{tabular}{|c|c|c|c|}
\hline & \\
\hline & $\begin{array}{l}\text { Intercepto } \\
\text { Intercept }\end{array}$ & $\beta$ & $\mathrm{r}^{2}$ \\
\hline $\begin{array}{l}\text { Proteína } \\
\text { Protein }\end{array}$ & 0,052632 & 0,705620 & $0,94 * * *$ \\
\hline $\begin{array}{l}\text { Gordura } \\
\text { Fat }\end{array}$ & $-5,911316$ & 2,972898 & $0,80 * * *$ \\
\hline
\end{tabular}

*** significativo $(P<0,001)$.

A relação entre o peso de corpo vazio (PCVZ) e o peso vivo (PV) dos animais utilizados neste trabalho foi estabelecida fazendo-se a regressão do PCVZ, em função do PV, chegando-se à equação:

PCVZ $=-15,4725+0,8703 \mathrm{PV}$ ou PV $=\underline{\mathrm{PCVZ}+15,4725}$

0,8703

Com base nessa equação, foram feitas as conversões de PCVZ em PV, de forma a se expressar as composições dos animais com base nos dois pesos.

Os conteúdos corporais totais de proteína e de gordura e as concentrações de proteína e gordura por kg de PCVZ e PV, estimadas com base nas equações apresentadas na Tabela 1 , bem como os conteúdos corporais totais e por kg de PCVZ e por PV de energia obtidos a partir dos conteúdos de proteína e gordura e dos respectivos equivalentes calóricos 5,6405 e 9,329 kcal/g, propostos pelo ARC (1980), são apresentados na Tabela 2, para animais com pesos vivos de 250 a $450 \mathrm{~kg}$ e pesos de corpo vazio de 200 a $400 \mathrm{~kg}$.

Observou-se redução, com o aumento do ganho de peso do animal, da concentração de proteína e elevação das concentrações de gordura e energia (Tabela 2). Estas mudanças decorrem da desaceleração do crescimento do tecido muscular e do desenvolvimento mais rápido do tecido adiposo com a elevação do peso do animal (Berg \& Butterfied, 1976; Grant \& Helferich, 1991). Neste trabalho, entretanto, observou-se lento acúmulo de gordura, refletindo o baixo valor energético da dieta (pastejo exclusivo). Mesmo para animais de $450 \mathrm{~kg}$ de PV, o teor de gordura corporal foi de apenas $14,8 \%$, mostrando não terem ainda atingido o nível de engorda adequado para o abate. No Brasil, o teor de gordura de animais acabados oscila, normalmente, de 21 a 24\%.

A composição corporal de bovinos, embora fortemente influenciada pela raça, pelo sexo e pela idade (maturidade), sofre influência do nível energético da dieta e, conseqüentemente, do nível de ganho de peso diário, conforme salientado pelo NRC (1996).

Resultados obtidos, no Brasil, com animais zebuínos e mestiços ganhando entre 1,0 e 1,3 kg por dia revelam teores de gordura e energia corporais mais elevados e teores de proteína mais baixos que os verificados neste trabalho. Entre os pesquisadores que desenvolveram estudos na área, Paulino et al. (1999b), trabalhando com animais Nelore, Gir, Guzerá e Mocho de Tabapuã, ganhando em média $1,3 \mathrm{~kg}$ de PCVZ por dia, durante o período de acabamento, ajustaram equações

Tabela 2 - Conteúdos corporais totais de proteína (PT) e gordura (GT) e conteúdos de proteína (P), gordura (G) e energia (CE), por kg de peso de corpo vazio (PCVZ) e peso vivo (PV), em função do PCVZ e do PV

Table 2 - Total body content of protein (TP) and fat (TF) and concentrations of protein (P), fat (F) and energy (E) per kg of empty body weight (EBW) and body weight (BW), as a function of EBW and BW

\begin{tabular}{|c|c|c|c|c|c|c|c|c|c|c|c|}
\hline \multirow[t]{2}{*}{$\begin{array}{l}\mathrm{PV}(\mathrm{kg}) \\
B W\end{array}$} & \multicolumn{2}{|c|}{$\begin{array}{l}\text { Peso total no PV } \\
\text { Total in } B W\end{array}$} & \multicolumn{3}{|c|}{$\begin{array}{l}\text { Concentração no PV } \\
\text { Concentration in BW }\end{array}$} & \multirow{2}{*}{$\begin{array}{c}\text { PCVZ }(\mathrm{kg}) \\
E B W \\
-\quad\end{array}$} & \multicolumn{2}{|c|}{$\begin{array}{l}\text { Peso total no PCVZ } \\
\text { Total in the EBW }\end{array}$} & \multicolumn{3}{|c|}{$\begin{array}{l}\text { Concentração no PCVZ } \\
\text { Concentration in the EBW }\end{array}$} \\
\hline & $\begin{array}{c}\text { PT (kg) } \\
\text { TP }\end{array}$ & $\begin{array}{l}\mathrm{GT}(\mathrm{kg}) \\
\mathrm{TF}\end{array}$ & $\mathrm{P}(\mathrm{g} / \mathrm{kg})$ & $\begin{array}{c}\mathrm{G}(\mathrm{g} / \mathrm{kg}) \\
F\end{array}$ & $\mathrm{E}(\mathrm{Mcal} / \mathrm{kg})$ & & $\begin{array}{c}\text { PT }(\mathrm{kg}) \\
\text { TP }\end{array}$ & $\begin{array}{c}\text { GT }(\mathrm{kg}) \\
\text { TF }\end{array}$ & $\mathrm{P}(\mathrm{g} / \mathrm{kg})$ & $\begin{array}{c}\mathrm{G}(\mathrm{g} / \mathrm{kg}) \\
F\end{array}$ & kg) \\
\hline 250 & 47,81 & 8,77 & 191 & 43 & 1,59 & 200 & 47,46 & 8,50 & 23 & 42 & 1,73 \\
\hline 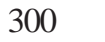 & 6 & & 18 & 6 & & 25 & 55 & 16 & 22 & & 1,87 \\
\hline 350 & 61,55 & 25,42 & 176 & 88 & 2,05 & 300 & 63,17 & 28,37 & 21 & 95 & 2,08 \\
\hline 400 & 67,94 & 38,56 & 170 & 116 & 2,27 & 350 & 70,43 & 44,87 & 201 & 128 & 2,34 \\
\hline 450 & 74,11 & 55,61 & 165 & 148 & 2,48 & 400 & 77,39 & 66,73 & 193 & 168 & 2,67 \\
\hline
\end{tabular}


alométricas, conforme o ARC (1980), para descrever as mudanças na composição corporal dos animais, de forma semelhante à deste trabalho. Utilizando-se as equações obtidas por esses autores, chega-aos conteúdos corporais de gordura de 86,2; 147,1 e 215,0 g por kg de PCVZ, para animais de 200, 300 e $400 \mathrm{~kg}$ de PCVZ, respectivamente. Esses valores superam em mais de $50 \%$ os obtidos para animais de mesmo peso, neste estudo, embora Paulino et al. (1999b) tenham utilizado animais não-castrados, que, em condições semelhantes de alimentação, apresentam níveis de gordura inferiores aos de animais castrados (utilizados nesta pesquisa). Para proteína, animais com esses pesos vivos teriam concentrações de 190,0; 176,5 e 167,6 g por kg de PCVZ, respectivamente, que são mais baixas que as encontradas neste trabalho, em função do efeito de diluição que o aumento do teor de gordura exerce sobre a concentração de proteína. As concentrações de energia verificadas por Paulino et al. (1999b) foram mais elevadas que as deste estudo, refletindo os teores corporais de gordura. Valores de gordura corporal igualmente mais elevados foram relatados por Fontes (1995), ao fazer uma análise conjunta de vários experimentos envolvendo animais castrados zebuínos e mestiços, obtidos por cruzamento entre raças zebuínas e raças taurinas de corte e leite, com ganhos de PCVZ de 1,0 a 1,2 kg, durante a fase de engorda. Para animais com 200, 300 e $400 \mathrm{~kg}$ de PCVZ, esse autor encontrou concentrações médias de gordura de 69, 134 e 216 g por kg de PCVZ, respectivamente.

Derivando-se as equações que descrevem o aumento dos conteúdos corporais de proteína e gordura obtidos nesta pesquisa, obtiveram-se as equações de predição do ganho de proteína e de gordura por kg de PCVZ ganho, apresentadas na Tabela 3.

Tabela 3 - Equações de predição do ganho de proteína e de gordura, em $\mathrm{kg}$, por kg de ganho de peso de corpo vazio (PCVZ) em função do PCVZ (X)

Table 3 - Prediction equations of protein and fat gain of steers, $k g$, per kg of empty body weight (EBW) gain, according to $E B W(X)$

\begin{tabular}{lc}
\hline $\begin{array}{l}\text { Componente } \\
\text { Component }\end{array}$ & $\begin{array}{c}\text { Equação de predição } \\
\text { Prediction equation }\end{array}$ \\
\hline $\begin{array}{l}\text { Proteína } \\
\text { Protein }\end{array}$ & $\mathrm{Y}^{\prime}=0,796531 * \mathrm{X}^{-0,29438}$ \\
$\begin{array}{l}\text { Gordura } \\
\text { Fat }\end{array}$ & $\mathrm{Y}^{\prime}=\left(3,646 * 10^{-6}\right) * \mathrm{X}^{1,9728979}$ \\
\hline
\end{tabular}

As concentrações de proteína e energia por unidade de ganho, para animais com PV entre 250 e $450 \mathrm{~kg}$ e para PCVZ entre 200 e $400 \mathrm{~kg}$, obtidas com base nas equações apresentadas na Tabela 2 , bem como os conteúdos de energia por unidade de peso ganho, calculados em função da composição do ganho e dos conteúdos calóricos de proteína e gordura (ARC, 1980), encontram-se na Tabela 4.

As concentrações de proteína no ganho reduziram, enquanto as de gordura e energia elevaram com o aumento do peso corporal dos animais, o que está de acordo com as observações do ARC (1980), de Geay (1984) e do NRC (1996) e com os resultados obtidos, no Brasil, por diversos autores (Lana et al., 1992a, b; Pires et al., 1993a, b; Fontes, 1995; Boin, 1995; Freitas et al., 2000; Berndt et al., 2002).

Os resultados deste trabalho, entretanto, diferem dos relatados pela maioria dos autores citados, em virtude da redução mais lenta na concentração de proteína e do menor aumento na concentração de gordura no ganho, com elevação do peso corporal dos animais. O menor acréscimo de gordura verificado, por kg de peso ganho, resultou em manutenção de proporções relativamente altas de proteína no ganho. Esses resultados são decorrentes do baixo nível de energia da dieta, no presente trabalho (pasto), em relação às dietas mais energéticas utilizadas pelos demais autores, as quais proporcionaram taxas de ganho de peso mais elevadas. Conforme salientado por Geay (1984) e NRC (1996), o conteúdo de gordura no ganho é influenciado pela taxa de ganho de peso.

Neste estudo, os animais tiveram ganho diário médio de 0,516 g de PCVZ, durante o período de 175 dias de pastejo. Contrapondo-se a estes resultados, Fontes (1995) observou, em bovinos castrados, zebuínos e diferentes mestiços Europeu-Zebu ganhando de 1 a 1,3 kg de PCVZ por dia, concentrações médias de proteína e gordura por kg de ganho de PCVZ, de 145 e 183 g; 127 e 356 g e 115 e 572 g, para animais com 200, 300 e 400 kg de PCVZ, respectivamente. Resultados de Paulino et al. (1993b) comprovam igualmente maiores concentrações de gordura e menores de proteína em zebuínos com taxa de ganho diária de 1,3 kg de PCVZ, embora os animais não fossem castrados e, portanto, apresentassem maior potencial para crescimento muscular. Com base nas equações ajustadas por esses autores, chegase, para animais com os mesmos pesos acima, às concentrações de proteína e gordura no ganho de 156 e 199 g; 145 e 340 g e 137 e 496 g por kg, respectivamente. 
Tabela 4 - Ganhos de proteína (P), gordura (G) e energia (E) por kg de ganho de peso vivo (GPV) ou de peso de corpo vazio (GPVZ), em função do peso vivo (PV) ou do peso de corpo vazio (PCVZ)

Table 4 - Gains of protein (P), fat ( $F)$ and energy (E) per $\mathrm{kg}$ of body weight gain (BWG) or empty body weight gain (EBWG), according to body weight (BW) or empty body weight (EBW)

\begin{tabular}{|c|c|c|c|c|c|c|c|}
\hline \multirow[t]{2}{*}{$\begin{array}{l}\mathrm{PV}(\mathrm{kg}) \\
B W\end{array}$} & \multicolumn{3}{|c|}{$\begin{array}{c}\text { Concentração no GPV } \\
\text { Concentration in BWG }\end{array}$} & \multirow[t]{2}{*}{$\begin{array}{c}\text { PCVZ }(\mathrm{kg}) \\
E B W\end{array}$} & \multicolumn{3}{|c|}{$\begin{array}{l}\text { Peso total no GPCVZ } \\
\text { Total in the EBWG }\end{array}$} \\
\hline & $\mathrm{P}(\mathrm{g} / \mathrm{kg})$ & $\begin{array}{c}\mathrm{G}(\mathrm{g} / \mathrm{kg}) \\
F\end{array}$ & E (Mcal/kg) & & $\mathrm{P}(\mathrm{g} / \mathrm{kg})$ & $\begin{array}{c}\mathrm{G}(\mathrm{g} / \mathrm{kg}) \\
F\end{array}$ & $\mathrm{E}$ (Mcal/kg) \\
\hline 250 & 167 & 129 & 2,15 & 200 & 167 & 126 & 2,13 \\
\hline 300 & 158 & 189 & 2,67 & 250 & 157 & 196 & 2,73 \\
\hline 350 & 150 & 261 & 3,30 & 300 & 149 & 281 & 3,48 \\
\hline 400 & 144 & 345 & 4,05 & 350 & 142 & 381 & 4,38 \\
\hline 450 & 139 & 439 & 4,90 & 400 & 137 & 496 & 5,43 \\
\hline
\end{tabular}

O ARC (1980) apresenta equações de predição dos conteúdos corporais de proteína e energia para bovinos castrados de porte médio, de raças européias, com ganho diário de $0,6 \mathrm{~kg}$ de PCVZ. Derivando-se as equações, chega-se às equações de predição da composição do ganho para animais com diferentes pesos corporais. Para animais ganhando 0,6 kg de PCVZ, com 200, 250, 300, 350 e 400 kg de PCVZ as concentrações estimadas de proteína e gordura seriam, respectivamente, 155 e 256 g; 151 e 305 g; 148 e 353 g; 145 e 398 g e 144 e 442 g. Quanto à essas estimativas, os animais deste experimento ganharam inicialmente mais proteína e menos gordura (entre 200 e 300 kg de PCVZ), passando, a partir de $350 \mathrm{~kg}$ de PCVZ, a depositar maior quantidade de gordura e menor de proteína. A diferença na partição da energia entre os tecidos muscular e adiposo evidenciada por estes resultados, em relação aos do ARC (1980), devem-se, provavelmente, ao regime nutricional anterior a que estiveram sujeitos os animais. As informações deste trabalho referem-se a animais criados em regime exclusivo de pastagem que passaram pelo período seco do ano sem suplementações, antes do início do experimento, que se desenvolveu no período chuvoso. As informações do ARC referem-se a animais que, durante todo o período de crescimento, apresentaram ganho médio de $0,6 \mathrm{~kg}$ por dia. Tem sido amplamente demonstrado que animais, após passarem por um período de restrição alimentar, apresentam, no início do período em que é restaurado o nível mais elevado de nutrição, maior deposição de proteína e menor de gordura e, posteriormente, passam a depositar mais gordura que animais não expostos a estresse nutricional (Rayan, 1990; Hoog, 1991; Sainz et al., 1995).
Os resultados obtidos neste trabalho, associados às informações de exigência de energia de mantença dos mesmos animais, em pastagem de capim-elefante, obtidas por Fontes et al. (2005), permitem inferências sobre os níveis de exigência de proteína e energia e sobre as mudanças na composição corporal e do ganho de peso, com o aumento do peso vivo, de animais pastejando forrageiras tropicais, uma vez que os ganhos de peso verificados neste trabalho enquadram-se perfeitamente nos níveis apresentados por Euclides (2001), para forrageiras tropicais, no Brasil.

As adequações das equações desenvolvidas neste estudo para predição da composição do peso corporal e do ganho de peso, bem como dos valores de $\mathrm{EL}_{\mathrm{m}}, \mathrm{EL}_{\mathrm{g}}$ do capim-elefante e das exigências de $\mathrm{EL}_{\mathrm{m}}$ dos novilhos encontrados pode ser evidenciada a partir dos cálculos abaixo, referentes a um novilho com $300 \mathrm{~kg}$ de PCVZ ganhando 0,516 g por dia.

Um novilho com $300 \mathrm{~kg}$ de PCVZ, admitindo-se a exigência de energia de mantença determinada por Fontes et al. (2005), para os mesmos animais e nas mesmas pastagens (exigência de $\mathrm{EL}_{\mathrm{m}}=63,27 \mathrm{kcal} / \mathrm{kg}$ $\mathrm{PCVZ}^{0,75}$ ), teria requerimento de $\mathrm{EL}_{\mathrm{m}}=4,56 \mathrm{Mcal} /$ dia. Com base nas informações deste trabalho, um animal de $300 \mathrm{~kg}$ de PCVZ ganharia 149 g de proteína e $281 \mathrm{~g}$ de gordura por kg de ganho de PCVZ, o que corresponderia a 3,48 Mcal de energia líquida. Admitindo-se o ganho médio diário de 0,516 kg observado neste trabalho, a exigência de energia líquida diária para ganho seria: $\mathrm{EL}_{\mathrm{g}}=3,48$ x 0,516 = 1,8 Mcal/dia.

Considerando-se os conteúdos obtidos de energia líquida do capim-napier (conteúdo de $\mathrm{EL}_{\mathrm{m}}=1,02$ $\mathrm{Mcal} / \mathrm{kg}$ de MS e conteúdo de $\mathrm{EL}_{\mathrm{g}}=0,59 \mathrm{Mcal} / \mathrm{kg}$ de MS), o nível total de consumo de MS para satisfazer 
as exigências diárias de um animal de $300 \mathrm{~kg}$ de PCVZ ganhando 0,516 g de PCV por dia seria:

Exigência de mantença $=4,56 \mathrm{Mcal} / \mathrm{dia} \div$

$$
1,02 \mathrm{Mcal} / \mathrm{kg} \mathrm{MS}=4,47 \mathrm{~kg} \text { de MS }
$$

Exigência de ganho $=1,80 \mathrm{Mcal} / \mathrm{dia} \div 0,59 \mathrm{Mcal} / \mathrm{kg} \mathrm{MS}=$

$$
\text { 3,05 kg de MS }
$$

Consumo diário de MS necessário = 7,52 kg de MS

Para os mesmos animais e período, Erbesdobler et al. (2002) observaram consumo médio de 2,16 kg de MS/100 kg de PV. Utilizando-se a equação de conversão de PCVZ em PV obtida neste estudo $\left(\mathrm{PV}=\frac{P C V Z+15,4725}{0,8703}\right)$, pode-se determinar que um animal de $300 \mathrm{~kg}$ de PCVZ corresponde a um animal de 362,5 kg de PV. Logo, esse animal consumiria, por dia, $\frac{362,5 \times 2,16}{100}=7,83 \mathrm{~kg}$ de MS. Este nível de consumo é, apenas, ligeiramente superior ao consumo estimado necessário para mantença e ao nível de ganho observado, com a composição de ganho estimada baseando-se nas equações ajustadas para os animais desta pesquisa.

\section{Conclusões}

A metodologia empregada para a determinação das concentrações de energia líquida para mantença $\left[E L_{m}\right]$ e ganho $\left[E L_{g}\right]$ do capim-napier, sob pastejo, proporcionou resultados consistentes, chegando-se a valores muito próximos aos propostos pelo NRC (1996), para a mesma forrageira, com idade de rebrota semelhante.

Bovinos castrados em fase de crescimento/engorda (200 a $400 \mathrm{~kg}$ de PCVZ), mantidos em regime exclusivo de pastejo, com ganho moderado de peso, apresentam concentrações superiores de proteína e inferiores de gordura corporal e maior ganho (g/kg ou $\mathrm{Mcal} / \mathrm{kg}$ de PCVZ), em relação aos valores relatados na literatura para animais de pesos correspondentes, alimentados em confinamento com rações mais energéticas, apresentando ganhos de peso diários mais elevados.

As informações obtidas neste trabalho permitem inferências sobre as mudanças na composição corporal e nas exigências de proteína e energia para ganho, com o aumento do peso corporal, de animais mantidos em regime exclusivo de pastejo, em forrageiras tropicais.

\section{Literatura Citada}

AgRiCUltural RESEARCH COUNCIL - ARC. The nutrient requirements of ruminants livestock. London: Commonwealth Agricultural Bureaux, 1980. 351p.

BERG, R.T.; BUTTERFIELD, R.M. New concepts of cattle growth. New York: Sydney University, 1976. 240p.

BERNDT, A.; HENRIQUE, W.; LEME, P.R. et al. Exigências líquidas de proteína e energia para crescimento de tourinhos Santa Gertrudes em dietas de alto teor de concentrado. Revista Brasileira de Zootecnia, v.31, n.5, p.2098-2104, 2002.

BISHOP, J.C.; FROSETH, J.A. Improved techniques in esophageal fistulization of sheep American Journal of Veterinarian Research, v.31, n.8, p.1505-1707, 1970.

BOIN, C. Alguns dados sobre exigências de energia e de proteína de zebuínos. In: SIMPÓSIO INTERNACIONAL SOBRE EXIGÊNCIAS NUTRICIONAIS DE RUMINANTES, 1995, Viçosa, MG. Anais... Viçosa, MG: JARD, 1995. p.457-465.

COMMONWEALTH SCIENTIFIC AND INDUSTRIAL RESEARCH ORGANIZATION - CSIRO. Feeding standards for Australian livestock-ruminants. Victoria: Australia Agricultural Council, 1990. 266p.

ERBESDOBLER, E.A.; FONTES, C.A.A.; QUEIROZ, D.S. et al. Avaliação do consumo e ganho de peso de novilhos em pastejo rotacionado de capim-elefante (Pennisetum purpureum, Schum.) cv. Napier, na estação chuvosa. Revista Brasileira de Zootecnia, v.5, p.2123-2128, 2002.

EUCLIDES, V.P.B. Produção intensiva de carne bovina em pasto. In: SIMPÓSIO DE PRODUÇÃO DE GADO DE CORTE, 2. 2001, Viçosa, MG. Anais... Viçosa, MG: Universidade Federal de Viçosa, 2001. p.55-82.

FONTES, C.A.A. Composição corporal, exigências líquidas de nutrientes para ganho de peso e desempenho produtivo de animais zebuínos e mestiços europeu-zebu. Resultados experimentais. In: SIMPÓSIO INTERNACIONAL SOBRE EXIGÊNCIAS NUTRICIONAIS DE RUMINANTES, 1995, Viçosa, MG, Anais... Viçosa, MG: JARD, 1995. p.419-455.

FONTES, C.A.A.; OLIVEIRA, R.C.; ERBESDOBLER, E.A. et al. Uso do abate comparativo na determinação da exigência de energia de mantença de gado de corte, pastejando capimelefante: descrição da metodologia e resultados. Revista Brasileira de Zootecnia, v.34, n.5, p.1721-1729, 2005.

FREITAS, J.A.; FONTES, C.A.A.; SOARES, J.E. et al. Composição corporal e exigências de energia de mantença de bovinos (zebuínos e mestiços) e bubalinos não castrados, em confinamento. Arquivo de Ciências Veterinárias e Zoologia - Unipar, v.3, n.1, p.19-29, 2000.

GEAY, Y. Energy and protein utilization in growing cattle. Journal of Animal Science, v.58, n.3, p.766-778, 1984.

GONÇALVES, L.C. Digestibilidade, composição corporal, exigências nutricionais e características das carcaças de zebuínos, taurinos e bubalinos. Viçosa, MG: Universidade Federal de Viçosa, 1988. 238p. Tese (Doutorado em Zootecnia) - Universidade Federal de Viçosa, 1988.

GRANT, A.L.; HELFERICH, W.G. An overview of growth. In: PEARSON, A.M.; DUTSON, T.R. (Eds.). Growth regulation in farm animals. London: Elsevier Applied Science, 1991. p.1-15.

HANKINS, O.G.; HOWE, P.E. Estimation of the composition of beef carcasses and cuts. Washington, D.C.: 1946. (Technical Bulletin - USDA, 926) 
HOGG, B.W. Compensatory growth in ruminants. In: PEARSON, A.M; DUTSON, T.R. (Ed). Growth regulation in farm animals. London: Elsevier Science, 1991. v.7, p.103-134.

JORGE, A.M.; FONTES, C.A.A.; PAULINO, M.F. Composição corporal de bovinos de quatro raças zebuínas, abatidos em diferentes estádios de maturidade. Revista Brasileira de Zootecnia, v.28, n.2, p.388-394, 1999.

KOCK, S.W.; PRESTON, R.L. Estimation of bovine carcass composition by the urea dilution technique. Journal of Animal Science, v.48, n.2, p.319-327, 1979.

LANA, R.P.; FONTES, C.A.A.; PERON, A.J. et al. Composição corporal e exigências de energia, proteína e macroelementos minerais (Ca, P, Mg, Na e K) de novilhos de cinco grupos raciais em confinamento. 1. Conteúdo corporal e do ganho de peso em gordura, proteína e energia. Revista da Sociedade Brasileira de Zootecnia, v.21, n.3, p.518-527, 1992a.

LANA, R.P.; FONTES, C.A.A.; PERON, A.J. et al. Composição corporal e exigências de energia, proteína e macroelementos minerais (Ca, P, Mg, Na e K) de novilhos de cinco grupos raciais em confinamento. 2. Exigências de energia e proteína. Revista da Sociedade Brasileira de Zootecnia, v.21, n.3, p.528-537, 1992b.

LANA, R.P.; FONTES, C.A.A.; PERON, A.J. et al. Composição corporal e exigências de energia, proteína e macroelementos minerais ( $\mathrm{Ca}, \mathrm{P}, \mathrm{Mg}$, Na e $\mathrm{K}$ ) de novilhos de cinco grupos raciais em confinamento. 3. Conteúdo corporal e do ganho de peso e exigências de macroelementos minerais. Revista da Sociedade Brasileira de Zootecnia, v.21, n.3, p.538-544, 1992c.

NATIONAL RESEARCH COUNCIL - NRC. Nutrient requirements of beef cattle. 7.ed. Washington, D.C.: 1996. 242p.

PAULINO, M.F.; FONTES, C.A.A.; JORGE, A.M. et al. Exigências de energia para mantença de bovinos zebuínos nãocastrados em confinamento. Revista Brasileira de Zootecnia, v.28, n.3, p.621-626, 1999a.

PAULINO, M.F.; FONTES, C.A.A.; JORGE, A.M. et al. Composição corporal e exigências de energia e proteína para ganho de peso de bovinos de quatro raças zebuínas. Revista Brasileira de Zootecnia, v.28, n.3, p.627-633, 1999b.

PIRES, C.C.; FONTES, C.A.A.; GALVÃO, J.G. et al. Exigências nutricionais de bovinos de corte em acabamento. I. Composição corporal e exigências de proteína para ganho de peso. Revista da Sociedade Brasileira de Zootecnia, v.22, n.1, p.110-120, 1993a.
PIRES, C.C.; FONTES, C.A.A.; GALVÃO, J.G. et al. Exigências nutricionais de bovinos de corte em acabamento. II. Exigências de energia para mantença e ganho de peso. Revista da Sociedade Brasileira de Zootecnia, v.22, n.1, p.121-132, 1993b.

ROCHA, E.O.; FONTES, C.A.A. Composição corporal, composição do ganho de peso e exigências nutricionais de novilhos de origem leiteira. Revista Brasileira de Zootecnia, v.28, n.1, p.159-168, 1999.

RYAN, W.J. Compensatory growth in cattle and sheep. Nutrition Abstracts and Reviews, v.60, p.653-664, 1990.

SAINZ, R.D.; DE LA TORRE, F.; OLTJEN, J.W. Compensatory gowth and carcass quality in growthrestricted and refed beef steers. Journal of Animal Science, v.73, n.10, p.2971-2979, 1995.

SALVADOR, M. Exigências de energia e proteína para engorda de novilhos azebuados. Viçosa, MG: Universidade Federal de Viçosa, 1980. 70p. Dissertação (Mestrado em Zootecnia) - Universidade Federal de Viçosa, 1980.

SIGNORETTI, R.D.; COELHO DA SILVA, J.F.; VALADARES FILHO, S.C. et al. Composição corporal e exigências líquidas de energia e proteína de bezerros da raça holandesa alimentados com dietas contendo diferentes níveis de volumoso. Revista Brasileira de Zootecnia, v.28, n.1, p.195-204, 1999.

SILVA, D.J. Análise de alimentos (métodos químicos e biológicos). Viçosa, MG: Universidade Federal de Viçosa, 1990. 165p.

SOARES, J.E. Composição corporal e exigências de macroelementos minerais (Ca, P, Mg, Na e K) para ganho de peso em bovinos (zebuínos e taurinos) e bubalinos. Viçosa, MG: Universidade Federal de Viçosa, 1994. 77p. Dissertação (Mestrado em Zootecnia) - Universidade Federal de Viçosa, 1994.

TEIXEIRA, J.C. Exigências de energia e proteína, composição e área corporal e principais cortes da carcaça em seis grupos genéticos de bovídeos. Viçosa, MG: Universidade Federal de Viçosa, 1984. 94p. Dissertação (Mestrado em Zootecnia) - Universidade Federal de Viçosa, 1984.

TILLEY, J.M.A.; TERRY, R.A. A two-stage technique for the in vitro digestion of forage crops. Journal British Grassland Society, v.18, n.2, p.104-111, 1963.

Recebido em: 16/10/04 Aceito em: 14/06/05 